\title{
Talking about bioelectrical potentials using rings of the mesenteric artery without glass micropipettes
}

\author{
H. V. Ribeiro-Filho, T. S. Brito, F. J. B. Lima, J. P. M. Pinho, D. F. Sousa, M. T. B. Silva, \\ R. J. B. de Siqueira, F. Cosker, V. P. D. Bastos, A. A. Santos, and P. J. C. Magalhães \\ Department of Physiology and Pharmacology, School of Medicine, Federal University of Ceará, Fortaleza, Ceará, Brazil
}

Submitted 23 March 2012; accepted in final form 27 August 2012

\begin{abstract}
Ribeiro-Filho HV, Brito TS, Lima FJ, Pinho JP, Sousa DF, Silva MT, de Siqueira RJ, Cosker F, Bastos VP, Santos AA, Magalhães PJ. Talking about bioelectrical potentials using rings of the mesenteric artery without glass micropipettes. Adv Physiol Educ 36: 336-344, 2012; doi:10.1152/advan.00050.2012.-In the present study, a practical activity is proposed to adopt an experimental approach to demonstrate the relationship between the equilibrium potential for $\mathrm{K}^{+}$and transmembrane electrical potential without glass micropipettes. A conventional setup for recording contractile activity of isolated smooth muscle preparations was used based on the events elegantly described by Somlyo and Somlyo in the 1960s. They showed that, in response to a given stimulus, smooth muscle cells may contract, recruiting electromechanical or pharmacomechanical coupling by mechanisms that involve, or not, changes in transmembrane potential, respectively. By means of contractions and relaxations of a ring-like preparation from the rat mesenteric artery, it is possible to observe the functional consequences of handling $\mathrm{K}^{+}$ concentration in the extracellular compartment and the effects caused by opening $\mathrm{K}^{+}$channels in that preparation, which are significant when the cell membrane establishes an electrical potential difference between intra- and extracellular compartments (driven mainly by $\mathrm{K}^{+}$permeability under resting conditions). The effects observed by students fit well with values predicted by Nernst and Goldman-Hodgin-Katz equations, and we demonstrated that the activity is able to improve students' comprehension regarding basic principles of bioelectricity.
\end{abstract}

resting potential; potassium equilibrium potential; Nernst equation; physiology education

THE MAJOR AIM of this activity was to construct a hands-on activity in which students have to demonstrate the relationship between the equilibrium potential for $\mathrm{K}^{+}$and transmembrane electrical potential without using glass micropipettes in classical electrophysiological techniques. Indeed, the activity used isolated smooth muscle ring-like pieces obtained from the rat mesenteric artery positioned in a conventional setup for contractile recordings. Such preparations may reveal valuable events related to membrane electrical behavior. Regarded as an excitable cell, smooth muscle is easily influenced by a variety of electrical currents in the plasmalemma, and changes in its membrane ion permeability result in changes in its contractile behavior. By applying contractile or relaxation stimuli and observing the subsequent trace deflections, it is possible to construct a relationship that fits well with classical equations used to predict electrical potential across the cell membrane. Thus, this activity offers to students a more clear comprehen-

Address for reprint requests and other correspondence: P. J. C. Magalhães, Departamento de Fisiologia e Farmacologia, Faculdade de Medicina, Universidade Federal do Ceará, Rua Cel. Nunes de Melo 1315, Fortaleza, Ceará 60.430-270, Brasil (e-mail: pjcmagal@ufc.br). sion of how bioelectrical potentials may be influenced by the membrane permeability of an ion such as $\mathrm{K}^{+}$, the most important electrolyte that physiologically determines the establishment of resting potential.

\section{Background}

Bioelectrical potential is considered one of the most difficult concepts to be grasped by undergraduate students, despite its obvious relevance to the functioning of physiological systems. Silverthorn (17) has already shown that biomedical students failed to correctly answer basic questions regarding this issue, even after a regular course in neurophysiology. As a matter of fact, students used to come to the class with a superficial understanding of the subject, and the distinctions among equilibrium potential, resting potential, and the consequences caused by changing extracellular ion concentrations may be source of confusion.

Recognizing this issue as a pedagogical challenge, several authors designed analogies to illustrate electrical cell phenomena possessing physiological importance. For instance, Milanick (14) proposed that the transmembrane potential concept may be understood by observing the color changes of a solution in a bucket by allowing the liquid flow, which represents ion conductance, from two or more carboys containing colored fluids. In another example, Cardozo (4) used springs to establish a relationship between ionic conductances and the potential across the cell membrane, according Hooke's law. Other alternatives include the didactical use of virtual tools to simulate experimental conditions that reproduce results obtained in classical works (1, 5, 20). All these demonstrative or virtual approaches may be useful since biomedical students usually react against the mathematical and physical reasoning (14).

In the present report, a model of practical activity is proposed as an alternative method to demonstrate the relationship between the equilibrium potential for $\mathrm{K}^{+}$and transmembrane electrical potential by means of an experimental approach using isolated rings made from the rat mesenteric artery. This activity is useful to demonstrate the role of bioelectrical potentials on cell functions, considering the particular example of vascular smooth muscle tonus assessed by a classical ring-like vascular preparation. Using conventional glass bath chambers to record the contractile activity of isolated smooth muscle preparations, this activity was based on events elegantly described by Somlyo and Somlyo (18). They showed that, in response to a given stimulus, smooth muscle cells may contract, recruiting electromechanical or pharmacomechanical coupling by mechanisms that involve, or not, changes in transmembrane potential, respectively. 
It is well known that the most sensitive and convenient manner for demonstrating the occurrence of electrical phenomena in cells is the electrical recording method. Indeed, intracellular recordings of the electrical behavior in mesenteric artery preparations are experimentally possible (10). However, the regular use of an instrumental setup typical for electrophysiological experiences may be limited in recurring practical lessons with a great number of participants because it may require previous training and careful handling of costly experimental preparations (21). Such an approach also includes the use of fragile glass micropipettes with tips of micrometric dimensions, which must be small enough to penetrate the cell membrane without too much damage or fluid leakage, but this makes the glass capillary end easily breakable when the micropipette is moved or when smooth muscle cells contract.

Experimental recordings of the contractile activity in isolated tissues have been traditionally used for more than a century and are suitable for resolving many scientific puzzles, including the pedagogical issues (22). To this particular purpose, this technique is especially advantageous because does not require costly equipment or the death of a large number of animals, its results are reliable and reproducible, the tissues are physiologically stable, and the handling is relatively simple. Moreover, smooth muscle cells are traditionally considered as excitable cells, i.e., they are capable of being activated by and reacting to a given stimulus induced, for instance, by a pharmacological agent or by changes in their membrane electrical potential.

Targeting the comprehension of how electrical phenomena may be translated in contractile or relaxation responses using pieces of blood vessels for a group of undergraduate students constitutes a challenge, especially when electrophysiological recordings are not used. Thus, the present activity gives to the student the notion of how functional and measurable these events can be by, for instance, applying a hyperpolarizing stimulus caused by pharmacologically elicited opening of $\mathrm{K}^{+}$ channels. The experimental methods described here may reveal the perception of how important permeability is in determining the electrical phenomena that result in the establishment of a smooth muscle cell response.

\section{Learning Objectives}

After completing this lesson, the student will be able to:

1. describe the forces leading to net inward or outward ionic flows across cell membranes

2. differentiate the concept of "equilibrium potential" from "transmembrane potential"

3 . explain the effects of altering the extracellular $\mathrm{K}^{+}$concentration on the equilibrium potential for $\mathrm{K}^{+}$and on the transmembrane potential

4. explain the effects of altering the membrane permeability for $\mathrm{K}^{+}$on the contractile behavior of vascular smooth muscle cells

5. measure contractile responses of smooth muscle preparations using in vitro methodology

6. predict the effects (electrical or contractile) induced by changes in the extracellular $\mathrm{K}^{+}$concentration or in its permeability through the plasma membrane of smooth muscle cells.

The present activity may be applied to undergraduate students of all biomedical areas and should be scheduled to happen during regular courses of physiology, especially after a theoretical unit concerning the principles of cell physiology, which includes initial concepts of bioelectrical potentials and smooth muscle contraction.

Before doing this activity, students should have a basic understanding of principles of cell physiology. In the laboratory, students should know how to use laboratory glassware products, calculate chemical concentrations, and prepare dilute solutions.

The activity may be planned to occur in a single 2 -h session.

\section{METHODS}

\section{Equipment}

To carry out this activity, the following materials are needed:

1. An isometric force transducer (one for each bath chamber, ML870B60/C-V, AD Instruments).

2. A signal amplifier (ideally one containing at least four channels, e.g., PowerLab 8/30, AD Instruments).

3. A microcomputer with data-acquisition software.

4. A compressed gas cylinder containing a gaseous mixture $(5 \%$ $\mathrm{CO}_{2}$ in $\mathrm{O}_{2}$ ) connected with the bath chamber.

5. A thermal circulator pump to maintain the bath chamber temperature at $37^{\circ} \mathrm{C}$.

Other materials. The following are other materials that can be used:

6. An isolated tissue organ bath chamber with 5-ml capacity (one for each tissue preparation). Such devices are offered by several suppliers worldwide (e.g., AD Instruments, Radnotti, and UgoBasile).

7. Small hand-made triangular pieces ( $\sim 7-\mathrm{mm}$ side length) made, e.g., of stainless steel wire (0.3-mm diameter), as commonly used in dentistry (to produce tension in orthodontic brackets). Such pieces should be passed through the vessel's lumen for tissue support to allow tension measurements (one pair for each ring-like segment, as shown in Fig. 1).

8. Cotton thread for the connection of the triangular pieces containing the tissues with the force transducer.

9. A petri dish for tissue handling before transfer to the bath chamber.

10. Salts and reagents of analytic grade $\left(\mathrm{NaCl}, \mathrm{KCl}, \mathrm{NaH}_{2} \mathrm{PO}_{4}\right.$, $\mathrm{MgSO}_{4} \cdot 7 \mathrm{H}_{2} \mathrm{O}, \mathrm{CaCl}_{2}, \mathrm{NaHCO}_{3}$, glucose, phenylephrine, and diazoxide).

11. Distilled water.

12. Assay tubes $(10 \mathrm{ml})$ for solution preparation and dilution.

13. Volume-adjustable single-channel pipettes (volume range: $5-1,000 \mu \mathrm{l})$.

Solutions. The following solutions can be used:

A. $\mathrm{KCl}$ solution $(3 \mathrm{M})$.

$B$. Modified Krebs-Henseleit solution (physiological saline solution) of the following composition (in $\mathrm{mM}$ ): $118.0 \mathrm{NaCl}, 5 \mathrm{KCl}, 1.18$ $\mathrm{NaH}_{2} \mathrm{PO}_{4}, 1.18 \mathrm{MgSO}_{4} \cdot 7 \mathrm{H}_{2} \mathrm{O}, 2.50 \mathrm{CaCl}_{2}, 25.0 \mathrm{NaHCO}_{3}$ and 11.1 glucose.

$C$. Phenylephrine (10 mM, Sigma) dissolved in distilled water and sonicated just before use.

D. Diazoxide (100 mM, Sigma) dissolved in $0.1 \mathrm{M} \mathrm{NaOH}$.

E. Solutions $A, C$, and $D$ must be diluted by adding the appropriate volumes directly into solution $B$ in the bath chamber to achieve the desired concentration, as described below.

\section{Animals}

This activity involves the use of pieces cut from the mesenteric artery cut transversally in ring-like segments $(\sim 5 \mathrm{~mm})$. For this purpose, male Wistar rats (250-300 g) may be obtained from local colonies maintained at research institutions. In our particular case, animals were obtained from the vivarium maintained by the Department of Physiology and Pharmacology (Federal University of Ceará, 


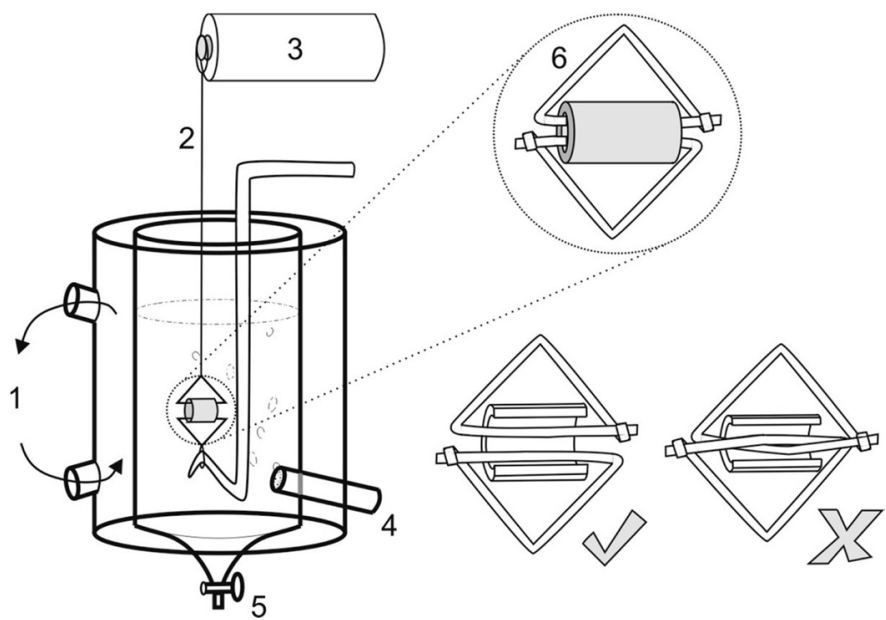

Fig. 1. Schematic representation of the isolated organ bath chamber. Shown is a graphic representation of a glass bath chamber containing a piece of the mesenteric artery cut as a ring-like segment, which should be immersed in Krebs-Henseleit physiological solution. The bath chamber typically possesses an external compartment, which should be connected to a thermal circulator pump (1). Rings were suspended on stainless steel triangular pieces, with one edge of each triangular device passed through the vessel's lumen for tension measurements using cotton thread (2) for connection of one triangular piece to the force transducer (3). The second triangular piece was connected on a fixed point inside the chamber. The bath chamber also allows oxygen bubbling (4) on its internal compartment, which may be drained through a point (5) in procedures for solution changes. In mounting the tissue with the small hand-made triangular pieces $(6)$, the operator must be aware of the parallel arrangement of steel devices $(\checkmark)$ and avoid the crossing of metal loops in the vessel's lumen (X).

Fortaleza, Ceará, Brazil). Animals were previously housed under standard conditions in polypropylene cages $(410 \times 340 \times 160 \mathrm{~mm})$ in groups of six rats with 12:12-h light-dark cycles with free access to food and water.

Animal welfare and experimental procedures were undertaken in accordance with the Ethical Principles for the Care and Use of Laboratory Animals of the Brazilian Society for Laboratory Animal Science (recorded in our institutional Animal Ethics Committee as protocol no. 16/2012).

Adopters of this activity are responsible for obtaining permission for animal research from their home institution. For "Guiding Principles for Research Involving Animals and Human Beings," please see www.the-aps.org/mm/Publications/Ethical-Policies/Animal-and-HumanResearch.

\section{Instructions}

Smooth muscle preparations. Rats were euthanized by stunning and exsanguination. Tissues were rapidly removed and immersed in a petri dish containing a physiological salt solution of Krebs-Henseleit solution ( $\mathrm{pH} 7.4$ at room temperature) to remove adhering fat and connective tissue under a microscope. Thereafter, smooth muscle preparations were suspended in conventional isolated bath chambers [four channels equipped with a 5-ml glass organ bath each, with the bath chamber filled with physiological salt solution $\left(\mathrm{pH} 7.4,37^{\circ} \mathrm{C}\right.$, continuously bubbled with $5 \% \mathrm{CO}_{2}$ in $\mathrm{O}_{2}$ )]. The smooth muscle preparations used were rings made from the superior mesenteric artery. Rings were suspended on stainless steel triangular pieces that had one of its edges passed through the vessel's lumen for tension measurements, as shown in Fig. 1.

Changes in muscle tension were measured isometrically by attaching the upper end of the ring to a force transducer connected to a digital data-acquisition system and are expressed in grams. Resting tension applied to preparations was $0.5 \mathrm{~g}$.
Experimental protocols. Before the activity began, an equilibration period of $1 \mathrm{~h}$ was allowed, and all tissues were then repeatedly stimulated with $60 \mathrm{mM} \mathrm{K}^{+}$to evaluate their viability. Preparations without reproducible contractions were substituted appropriately. This procedure was executed until the observation of two successive contractions with a similar amplitude, which signaled that the preparations were equilibrated.

Experiments were performed with tissue preparations maintained under resting tonus or on the steady state of a sustained contractile stimulus induced by a pharmacological agent $\left(\mathrm{K}^{+}\right.$, phenylephrine, or a combination of them). It is well known that increased $\mathrm{K}^{+}$concentrations are able to contract smooth muscle because depolarization occurs (3), whereas phenylephrine contracts smooth muscle as a result of $\alpha_{1}$-adrenoceptor stimulation, which typically elicits a biphasic response: an initial phasic component due to inositol 1,4,5-trisphosphate-induced intracellular $\mathrm{Ca}^{2+}$ release from the sarcoplasmic reticulum followed by a sustained phase, depending on dihydropyridine-insensitive $\mathrm{Ca}^{2+}$ influx through receptor-gated $\mathrm{Ca}^{2+}$ channels $(2,15)$.

Concentration-effect curves for $\mathrm{K}^{+}$were obtained by exposing the preparation to cumulatively increasing concentrations of $\mathrm{K}^{+}(5-120$ $\mathrm{mM}$ ), which were added hypertonically to the bath from a $3 \mathrm{M} \mathrm{KCl}$ solution and maintained at a given concentration for $3 \mathrm{~min}$. Hypertonic addition was chosen to obtain trace recordings without handling artifacts, which could be induced in the case of a full change of the bath solution. To measure the relaxation of muscle tonus, a ring of the precontracted mesenteric artery with either a given $\mathrm{K}^{+}$concentration or phenylephrine $(1 \mu \mathrm{M})$ was exposed to diazoxide $(100 \mu \mathrm{M})$, and its relaxation was taken as the difference between baseline on the plateau observed at a given concentration and baseline immediately before the addition of diazoxide. Contractions or relaxations were measured at the peak deflections.

Use of equations. Two equations were used for calculations of the electrical differences across the cell's membrane. The equation elaborated by Walther Nernst in the 19th century was used to describe the equilibrium potential for $\mathrm{K}^{+}$considering that the membrane was virtually permeable exclusively to this ion.

$$
E_{\mathrm{K}}=\frac{R \mathrm{~T}}{z F} \ln \frac{[\mathrm{K}]_{\text {out }}}{[\mathrm{K}]_{\text {in }}}=2.303 \frac{R \mathrm{~T}}{z F} \log _{10} \frac{[\mathrm{K}]_{\text {out }}}{[\mathrm{K}]_{\text {in }}}=61.5 \log _{10} \frac{[\mathrm{K}]_{\text {out }}}{[\mathrm{K}]_{\text {in }}}(1)
$$

Here, the equilibrium potential for $\mathrm{K}^{+}\left(E_{\mathrm{K}}\right)$ is assumed as the voltage difference between extra- and intracellular compartments at equilibrium, $R$ is the gas constant, $\mathrm{T}$ is the absolute temperature, $z$ is the valence of the ion in question $\left(+1\right.$ for $\mathrm{K}^{+}$), and $F$ is Faraday's constant. Such an equation was simplified assuming that the relationship of $2.303(R \mathrm{~T} / z F)$ was $61.5 \mathrm{mV}$ at $37^{\circ} \mathrm{C}$ for calculations with $\log _{10}$ instead of $\ln .[\mathrm{K}]_{\text {out }}$ and $[\mathrm{K}]_{\text {in }}$ are the concentrations of $\mathrm{K}^{+}$in the extracellular and cytoplasmic compartments, respectively, which were assumed to be the values shown in Table 1 .

Students also had to calculate the relation among membrane potential, ion concentrations, and relative ionic permeability using the

Table 1. Extracellular and cytoplasmic free ion concentrations considered in the present activity

\begin{tabular}{lccc}
\hline \hline Ion & $\begin{array}{c}\text { Extracellular } \\
\text { Concentration, mM }\end{array}$ & $\begin{array}{c}\text { Cytoplasmic } \\
\text { Concentration, mM }\end{array}$ & $\begin{array}{c}\text { Permeability } \\
\text { Ratio }\end{array}$ \\
\hline $\mathrm{Na}^{+}$ & 144 & 6 & 1 \\
$\mathrm{~K}^{+}$ & 5 & 120 & 6 \\
$\mathrm{Cl}^{-}$ & 125 & 42 & 3 \\
\hline
\end{tabular}

Hypothetical values for the internal concentrations of $\mathrm{Na}^{+}, \mathrm{K}^{+}$, and $\mathrm{Cl}^{-}$ were adopted for this activity. For cytoplasmic concentrations, data of Jacobson et al. (10) for vascular smooth muscle cells were used. Permeability ratio values were adopted based on absolute values measured in rat mesenteric vessels as reported by Videbaek et al. (21). 
Goldman-Hodgkin-Katz equation (Eq. 2) derived in the 1940s. This equation is similar to Nernst equation except that it simultaneously takes into account the contributions of the permeant ions $\mathrm{K}^{+}, \mathrm{Na}^{+}$, and $\mathrm{Cl}^{-}(7,11)$. Cell permeability values for these electrolytes were assumed as 6,1 , and 3, respectively, according to values provided by Videbaek et al. (23) using rat mesenteric vessels (Table 1). This equation was also used as its simplified form assuming the same relationship of $2.303(R \mathrm{~T} / z F)$ as adopted for Nernst equation, as follows:

$$
E_{\mathrm{m}}=61.5 \log _{10} \frac{P_{\mathrm{K}}[\mathrm{K}]_{\text {out }}+P_{\mathrm{Na}}[\mathrm{Na}]_{\text {out }}+P_{\mathrm{Cl}}[\mathrm{Cl}]_{\text {in }}}{P_{\mathrm{K}}[\mathrm{K}]_{\text {in }}+P_{\mathrm{Na}}[\mathrm{Na}]_{\text {in }}+P_{\mathrm{Cl}}[\mathrm{Cl}]_{\text {out }}}
$$

where $E_{\mathrm{m}}$ is transmembrane potential, $P$ is permeability, $[\mathrm{Na}]_{\text {out }}$ and $[\mathrm{Na}]_{\text {in }}$ are the concentrations of $\mathrm{Na}^{+}$in the extracellular and cytoplasmic compartments, and $[\mathrm{Cl}]_{\text {out }}$ and $[\mathrm{Cl}]_{\text {in }}$ are the concentrations of $\mathrm{Cl}^{-}$in the extracellular and cytoplasmic compartments.

Statistical analysis. Data in this report are expressed as means \pm $\mathrm{SE}$ of five to eight experiments. Significance of the results was determined using an unpaired Student's $t$-test or one-way ANOVA as appropriate. When ANOVA was significant, it was followed by a Holm-Sidak multiple-comparison test. Statistical significance was accepted when $P<0.05$.

Student groups. Undergraduate students were divided into four groups. Each group was assigned to carry out one entire protocol. Each bench had a ring of the mesenteric artery mounted as previously described in a bath chamber. Next, they were instructed to read the syllabus and perform the experiments under direct supervision of undergraduate and postdoc assistants; all trainees were accompanied by a lecturer.

Timeline of events. The activity began with a discussion about bioelectrical potentials, starting from a graphic representation of a virtual smooth muscle cell. Students should realize, as shown in Fig. 2 (and in Table 1), that the intracellular $\mathrm{K}^{+}$concentration is higher in the smooth muscle cells than in the extracellular medium (120 and $5 \mathrm{mM}$, respectively). So, two questions were presented to the students as a challenge: 1) What are the consequences of adding exogenously substantial amounts of $\mathrm{K}^{+}$to the extracellular compartment and 2) What are the consequences of opening $\mathrm{K}^{+}$channels in the plasmalemma? Students were stimulated to answer these questions by considering the effects on the transmembrane electrical potential and force development of the smooth muscle cell. Expected responses were both a decrease (less negative difference) in the transmembrane electrical potential and contraction under the exogenous addition of $\mathrm{K}^{+}$into the extracellular medium and an increase (more negative difference) in the transmembrane electrical potential and relaxation of smooth muscle cells after $\mathrm{K}^{+}$channel opening in the plasmalemma. After the discussion, students were invited to confirm their responses by means of experimental procedures. Additional details of the remaining steps that could be executed by the students are described in the RESULTS.

\section{Troubleshooting}

Some mistakes can produce technical problems, mainly when related to impairment of temperature maintenance $\left(\sim 37^{\circ} \mathrm{C}\right)$, air bubbling, or $\mathrm{pH}$ control (7.4). Care must be taken in relation to the volumes pipetted into bath chamber to avoid errors in solution concentrations. In mounting the tissue with the small hand-made triangular pieces, the operator must be aware of the fact that the pair of devices must be in parallel arrangement. Crossing of metal loops in the vessel's lumen, as shown in Fig. 1, may prevent trace recordings, even if force is developed by the tissue.

\section{Safety Considerations}

The present activity exposes students to minimal risks. Bench assembly is performed before the students' arrival to the laboratory due to the time scheduled for the activity execution, avoiding students' exposure to surgical procedures for obtaining animal tissue. The substances used in practice are of low toxicity and include physiological salt solutions with handling of $\mathrm{K}^{+}$concentrations by pipetting $\mathrm{KCl}$ within the bath chamber. Diazoxide (Chemical Abstracts Service no. 364-98-7, European Commission no. 206-668-1) is used as concentrated solution $(100 \mathrm{mM})$ brought to the chosen concentration by pipetting it within the bath chamber to achieve the desired concentration of $100 \mu \mathrm{M}$. Diazoxide has the following Material Safety Data Sheet warnings: may be harmful if swallowed, causes skin irritation, causes serious eye irritation, and may cause respiratory irritation. Pipette tips should be discarded properly after each procedure. Students should wear the appropriate personal protection equipment.

\section{RESULTS AND DISCUSSION}

\section{Expected Results}

Contraction of rings of the rat mesenteric artery. After the initial discussion, students performed a typical concentrationeffect curve by cumulatively increasing the extracellular $\mathrm{K}^{+}$ concentration (from 5 to $120 \mathrm{mM}$ ). Such procedures were able to demonstrate that by increasing $\mathrm{K}^{+}$outside the cell, smooth muscle cells may contract in a concentration-dependent manner (see question 1 above). Typical trace recordings of the results obtained in this first step of the experimental activity are shown in Fig. 3.

To confirm the question of what happens when $\mathrm{K}^{+}$channels in the plasmalemma open, students were instructed to add a given concentration of diazoxide $(100 \mu \mathrm{M})$, a well-known $\mathrm{K}^{+}$ channel opener (19), in the presence of the highest extracellular $\mathrm{K}^{+}$concentration $(120 \mathrm{mM})$. As shown in Fig. 3A, such an addition was unable to induce relaxant responses in the trace

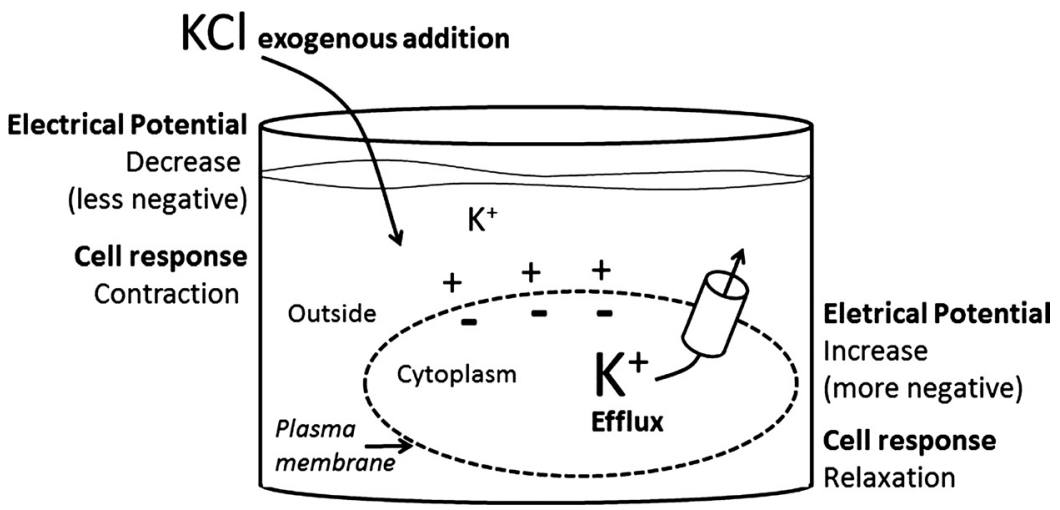

Fig. 2. Schematic representation of a smooth muscle cell. Shown is a graphic representation of the extracellular (outside) and cytoplasmic compartments separated by the plasma membrane. In this hypothetical example, $\mathrm{K}^{+}$represents a concentration of $\mathrm{K}^{+}$, and the font size indicates that it is higher (120 $\mathrm{mM}$ ) inside the cell than in the outside compartment $(5 \mathrm{mM})$. The electrical potential difference across the plasma membrane under resting conditions is also shown: positively charged outside the cell and negatively charged on its inner surface. 
A

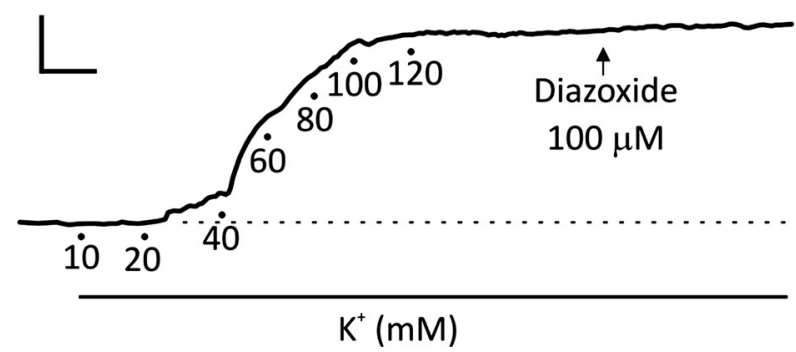

B

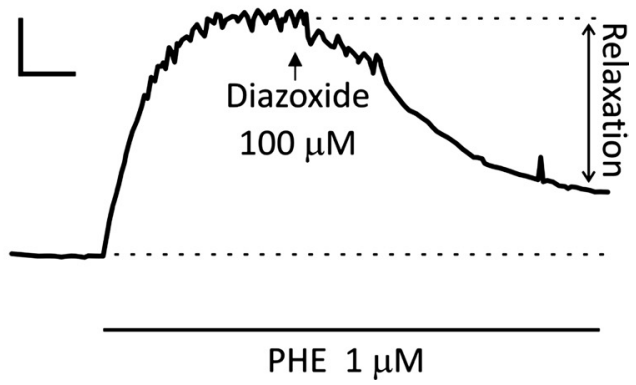

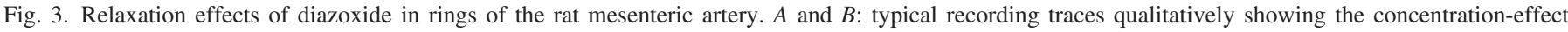

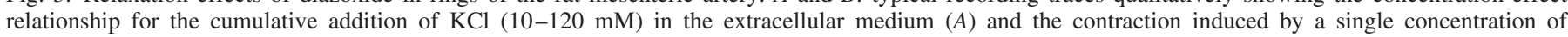

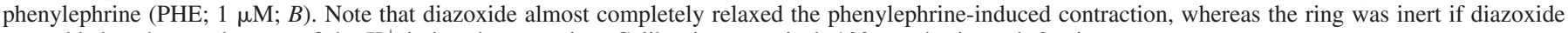
was added at the steady state of the $\mathrm{K}^{+}$-induced contraction. Calibrations: vertical, $100 \mathrm{mg}$; horizontal, $3 \mathrm{~min}$.

recording. Upon this occasion, students should answer the following question: why did the opening of $\mathrm{K}^{+}$channels fail to promote a relaxant effect?

To exclude a putative subeffective concentration of diazoxide in this experiment, another experimental procedure was proposed (Fig. 3B). After mesenteric rings had been returned to the basal condition through a complete substitution of bath solution to bring the extracellular $\mathrm{K}^{+}$concentration to the physiological level, the vascular preparation was contracted again, but now with phenylephrine $(1 \mu \mathrm{M})$ instead of $\mathrm{K}^{+}$as the contractile agent. As shown in Fig. 3, the same diazoxide concentration almost completely relaxed the contraction elicited by this adrenergic agonist.

Discussion of the results with classical equations. At this point, students were questioned again about the electrical events caused by the increasing $\mathrm{K}^{+}$concentration in the extracellular medium, as previously discussed. Students were then stimulated to express these electrical events quantitatively. For this purpose, the Nernst equation (Eq. I) was initially adopted. Students compiled the values shown in Table 2, which shows increasing $\mathrm{K}^{+}$concentrations, many of them used in the concentration-effect curve shown in Fig. 3 and the correspondent values of the electrical potential difference for each $\mathrm{K}^{+}$concentration as predicted by the Nernst equation. They were asked to reflect about the results shown in Table 2,

Table 2. Values of $E_{K}, E_{m}$, and $E_{m}^{\prime}$ as the extracellular $K^{+}$ increases from 5 to $120 \mathrm{mM}$

\begin{tabular}{cccc}
\hline \hline $\begin{array}{c}\text { Extracellular } \mathrm{K}^{+} \\
\text {Concentration, } \mathrm{mM}\end{array}$ & $E_{\mathrm{K}}, \mathrm{mV}$ & $E_{\mathrm{m}}, \mathrm{mV}$ & $E_{\mathrm{m}}^{\prime}, \mathrm{mV}$ \\
\hline 5 & -80.0 & -34.7 & -52.2 \\
10 & -66.4 & -32.2 & -46.2 \\
20 & -47.9 & -27.7 & -37.2 \\
30 & -37.0 & -23.9 & -30.5 \\
40 & -29.3 & -20.6 & -25.2 \\
50 & -23.4 & -17.6 & -20.7 \\
60 & -18.5 & -14.9 & -16.9 \\
70 & -14.4 & -12.5 & -13.5 \\
80 & -10.8 & -10.3 & -10.6 \\
90 & -7.7 & -8.2 & -7.9 \\
120 & 0 & -2.8 & -1.7 \\
\hline
\end{tabular}

$E_{\mathrm{K}}$, equilibrium potential of $\mathrm{K}^{+} ; E_{\mathrm{m}}$, transmembrane potential. $E_{\mathrm{m}}^{\prime}$ is the estimated $E_{\mathrm{m}}$ after an increase of the $\mathrm{K}^{+}$permeability in the cell membrane (from 6 to 18) caused, for instance, by the addition of a $\mathrm{K}^{+}$channel opener [based on Videbaek et al. (21)] (see the RESULTS AND DISCUSSION). and tutors reinforced the concept that the Nernst equation refers to the electrical potential difference that would be seen if a system in equilibrium is composed only by $\mathrm{K}^{+}$and a given impermeable anion through a membrane that separates two compartments containing different concentrations of these constituents.

Students were aware that live cells, like those in the experimental tissue, are obviously more complex than the virtual cell shown in Fig. 2. If the membrane allows other different ions to flow through its channels, other theoretical tools, such as the Goldman-Hodgkin-Katz model (Eq. 2), could be more appropriate to predict the resulting transmembrane electrical potential, because it includes the influence of two permeant cations $\left(\mathrm{Na}^{+}\right.$and $\left.\mathrm{K}^{+}\right)$and one permeant anion $\left(\mathrm{Cl}^{-}\right)$. Thus, students were stimulated to complete their table using this equation. Once completed, the table revealed a different profile for the values obtained with this equation compared with that of the Nernst equation. Next, students were invited to transfer these values to a graphic representation, in which $x$-axis indicated the concentration of $\mathrm{K}^{+}$and the $y$-axis indicated the predicted values for transmembrane potential, as shown in Fig. 4.

Back to the bench. Students were alerted to note an interesting detail obtained from the graph (Fig. 4). Diazoxide was unable to relax the contraction promoted by $120 \mathrm{mM} \mathrm{K}^{+}$, and such a lack of efficacy occurred at a concentration in which the theoretical value of the electrical potential (assumed as the result of the Goldman-Hodgkin-Katz equation) has an almost similar magnitude of the result given by the Nernst equation. Afterward, students were questioned as whether different relaxation results would be observed if diazoxide was added on the steady state of contractions induced by smaller $\mathrm{K}^{+}$concentrations. Thus, they performed additional procedures with several concentrations chosen from the concentration range where the predicted results differed from one another. The response to this question is shown in Fig. 5. As shown in Fig. 5, the smaller the $\mathrm{K}^{+}$concentration, the higher the relaxation effect of diazoxide on the $\mathrm{K}^{+}$-induced contraction.

What does the relaxation effect of diazoxide on the phenylephrine-induced contraction mean? Next, students were alerted to observe the results when phenylephrine was used as a contractile agent, especially at $5 \mathrm{mM}$ extracellular $\mathrm{K}^{+}$, a concentration that theoretically maximizes the difference between values predicted by Eqs. 1 and 2. Thus, to confirm that this difference is a factor that determines the efficacy of diazoxide, students 


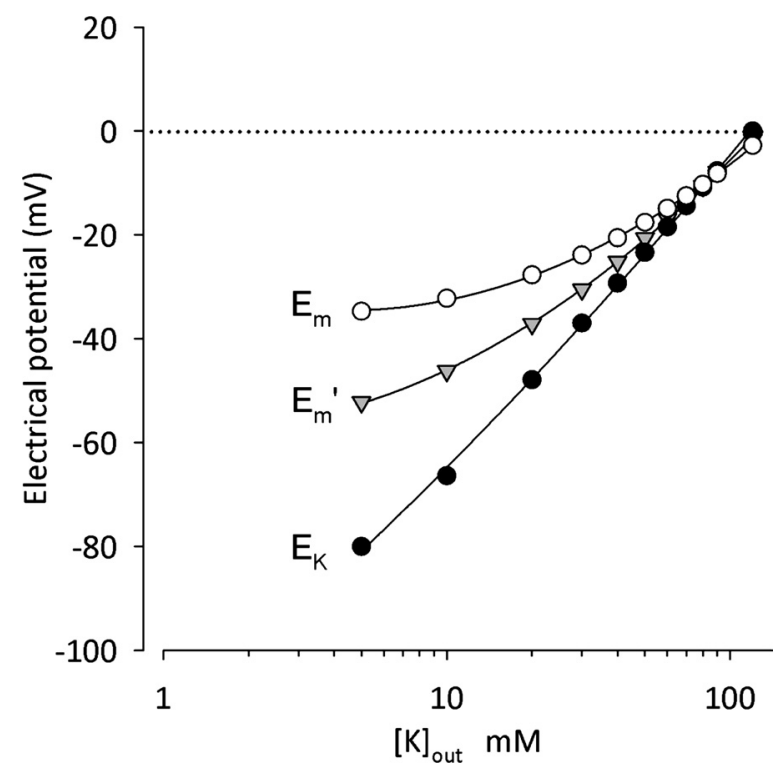

Fig. 4. Graphic representation of the dependence of the electrical potential on the extracellular $\mathrm{K}^{+}$concentration $\left([\mathrm{K}]_{\text {out }}\right.$ ) in a smooth muscle cell of the rat mesenteric artery. The graph was constructed according to the values shown in Table 2. Ionic concentrations for $\mathrm{Na}^{+}$and $\mathrm{Cl}^{-}$, as well as their respective membrane permeabilities, were considered constant. $E_{\mathrm{m}}$, transmembrane potential; $E_{\mathrm{m}}^{\prime}$ estimated $E_{\mathrm{m}}$ after an increase of $\mathrm{K}^{+}$permeability in the cell membrane; $E_{\mathrm{K}}$, equilibrium potential for $\mathrm{K}^{+}$. To obtain the $E_{\mathrm{m}}^{\prime}$ curve, the $\mathrm{K}^{+}$ permeability was considered as 18 in the Goldman-Hodgkin-Katz equation, according to the effect caused by a $\mathrm{K}^{+}$channel opener in rat mesenteric vessels [Videbaek et al. (21)].

were invited to perform additional experiments initially maintaining preparations contracted using a solution with a high $\mathrm{K}^{+}$ concentration (e.g., $60 \mathrm{mM}$, since it is submaximal). Once the contraction induced by $\mathrm{K}^{+}$treatment attained a steady state, phenylephrine $(1 \mu \mathrm{M})$ was added, a procedure that further contracted the mesenteric ring preparation, increasing the baseline beyond the level reached by solely by the addition of $\mathrm{K}^{+}$. Under such conditions, the addition of diazoxide $(100 \mu \mathrm{M})$ induced only a slight relaxation effect on the phenylephrineinduced contraction, which was significantly lower than that observed under physiological levels of $\mathrm{K}^{+}$(Fig. 6).

\section{Misconceptions}

This activity was initiated by an intriguing question, as shown in Fig. 2. Initially, most of the students could not explain the effects caused by the addition of $\mathrm{K}^{+}$into the extracellular compartment where smooth muscle cells are immersed. Although it was not quantitatively evaluated in the present work, students' responses during classes often revealed a recurrent misconception: if one adds a given amount of $\mathrm{K}^{+}$ into the extracellular medium (which is already electrically positive in relation to the intracellular medium), the transmembrane potential would be more negative simply because more $\mathrm{K}^{+}$outside makes the inside more negative, as similarly diagnosed by Silverthorn (17). Thus, the present exercise led students to realize that the addition of $\mathrm{K}^{+}$is accompanied by an equivalent amount of $\mathrm{Cl}^{-}$and, hence, there is no exclusive addition of positive charges to the extracellular medium. In fact, by adding $\mathrm{KCl}$, an increase in the extracellular $\mathrm{K}^{+}$ concentration was effectively promoted, reducing its chemical gradient between the intracellular and extracellular compart- ments, which is favorable to induce net $\mathrm{K}^{+}$efflux under physiological conditions. As a consequence of this reduced chemical gradient, a smaller electrical difference could be generated, as demonstrated by the Nernst equation. The value obtained using this equation (which is expressed in $\mathrm{mV}$ ) means that virtually an electrochemical equilibrium in which the opposed influences of the concentration and electrical gradients on $\mathrm{K}^{+}$movements will exactly balance one another (13).

Initially, students may conclude that by adding $\mathrm{K}^{+}$cumulatively from an exogenous source, smooth muscle cells would be depolarized. They visualized how a gradual depolarization may occur using the Nernst equation and experimentally confirmed that contractile responses may be produced. Thus, depolarization may be putatively related to the increasing $\mathrm{K}^{+}$-induced contraction, and this event represents activation of a voltage-dependent pathway. On the other hand, if $\mathrm{K}^{+}$selective ion channels are eventually opened in the plasmalemma, $\mathrm{K}^{+}$may be leaked from the cytoplasmic compartment (i.e., net efflux of positive charges from the cell) and then increase the negative difference between extracellular and intracellular compartments. So, contrary to the exogenous addition of $\mathrm{K}^{+}$, the opening of $\mathrm{K}^{+}$channels may produce vascular relaxation. However, it is worth noting that diazoxide produced no relaxation when added to preparations maintained under the highest $\mathrm{K}^{+}$concentration. Such a result sounds astonishing to students, but it should be reinforced that, once exposed to such a high $\mathrm{K}^{+}$concentration, the cell did not more possess a chemical gradient favorable for transfer of $\mathrm{K}^{+}$ toward the outside compartment, since $\mathrm{K}^{+}$is considered at the same concentration as within the cytoplasm (Table 1). Other reasons may be involved in this phenomenon, but it appears interesting that the functional consequence of the opening of $\mathrm{K}^{+}$channels depends both on the cell membrane potential and the chemical gradient of the permeable ion, which are collectively known as the "electrochemical gradient."

The hypothesis of a putative subeffective concentration of diazoxide (as raised in Expected Results) just functions as an artifice to show that the expected relaxant effect would be found if students used phenylephrine as a contractile agent. The different effects of diazoxide on $\mathrm{K}^{+}$and phenylephrineinduced contractions then became obvious. At this time, students may perceive that phenylephrine was added in a solution containing physiological levels of $\mathrm{K}^{+}(5 \mathrm{mM})$. The key step in this practice is the fact that different results were obtained when the students used Nernst and Goldman-Hodgkin-Katz equations.

Indeed, the results obtained using the Goldman-HodgkinKatz equation yielded values less negative than those calculated by the Nernst equation, especially considering the small $\mathrm{K}^{+}$concentrations outside the cell (Table 2). Since the influence of other different ionic conductances is inserted in results predicted by the Goldman-Hodgkin-Katz equation, the students should be aware that the relaxation effects of diazoxide are due to a selective increase in membrane permeability to $\mathrm{K}^{+}$. According to the present results, diazoxide relaxes the vascular tissues precontracted with $\mathrm{K}^{+}$just at a concentration range of extracellular $\mathrm{K}^{+}$in which the predicted line of Nernst and Goldman-Hodgkin-Katz equations clearly dissociate one another. As shown in Fig. 5, the magnitude of the relaxation effect caused by diazoxide follows an incremental pattern as the $\mathrm{K}^{+}$concentration decreases. Interestingly, as predicted by 
A

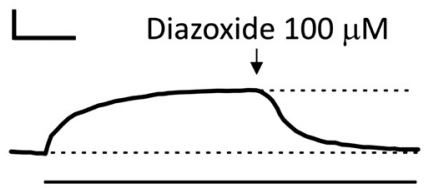

$\mathrm{K}^{+} 30 \mathrm{mM}$

Fig. 5. Relaxation effects of diazoxide in rings of the rat mesenteric artery exposed to several $\mathrm{K}^{+}$ concentrations. $A-D$ : typical recording traces showing the gradual lack of diazoxide $(100 \mu \mathrm{M})$ to relax smooth muscle contraction induced by increasing concentrations of $\mathrm{K}^{+}$(30-60 mM). Diazoxide was added at the steady state of a given $\mathrm{K}^{+}$-induced contraction. Calibrations: vertical, $100 \mathrm{mg}$; horizontal, 3 min. E: graph showing the mean values of relaxation, which are expressed as percentages of each $\mathrm{K}^{+}$-induced contraction. $F$ : graph showing the best-fit line traced by a linear regression for the change between $E_{\mathrm{K}}$ and $E_{\mathrm{m}}$ and between the relaxation effects of diazoxide at increasing $\mathrm{K}^{+}$concentrations. A correlation analysis reported a significant value of $0.8202(P<0.05)$ for the Pearson correlation coefficient $\left(R^{2}\right)$. Data are means \pm SE. $* P<$ 0.05 compared with values in the absence of diazoxide (by Holm-Sidak test).
B

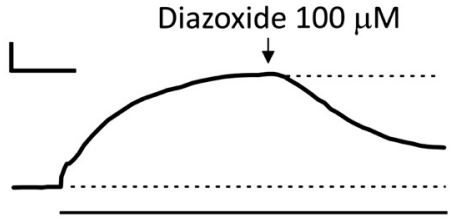

$\mathrm{K}^{+} 40 \mathrm{mM}$
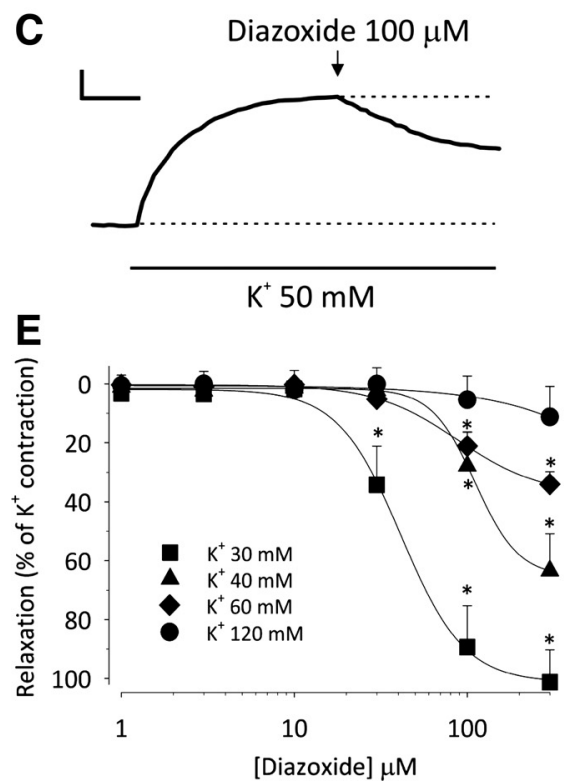

$\mathbf{F}$

$\mathrm{K}^{+} 60 \mathrm{mM}$

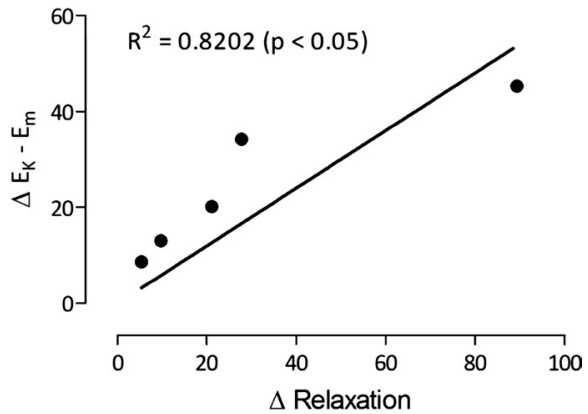

the classical equations, the magnitude of the difference between the values for the electrical potential also followed a similar incremental pattern, i.e., the smaller the $\mathrm{K}^{+}$concentration, the higher the difference between electrical potential values calculated by the Nernst equation from those obtained from the Goldman-Hodgkin-Katz equation.

Our perception is that the experimental observations described here may offer to students the opportunity to realize the importance of permeability in determining electrical phenomena across the membrane and the role of electrical transmembrane potential in the function of smooth muscle cell. The opening of $\mathrm{K}^{+}$channels makes $\mathrm{K}^{+}$proportionally more permeable than other ions, but this phenomenon appeared functionally evident (by means, for instance, of a measurable relaxation in the vascular tissue) just at extracellular $\mathrm{K}^{+}$ concentrations nearest to those found physiologically (16). Such a condition was present in preparations contracted with phenylephrine, which contracts smooth muscle cells by pharmacomechanical coupling (18). This means that opening of $\mathrm{K}^{+}$ channels may promote hyperpolarization, observed theoretically by students as the shift occurring in the membrane potential toward the $\mathrm{K}^{+}$equilibrium potential (predicted as $-80 \mathrm{mV}$ by the Nernst equation; Table 2). When students hypothetically increased $\mathrm{K}^{+}$permeability by three times in the Goldman-Hodgking-Katz equation (i.e., from 6 to 18), the resulting value for the transmembrane potential was around $-52.2 \mathrm{mV}$, a value more negative than the predicted -34.7 $\mathrm{mV}$ originally calculated in this activity.

In contrast, the ability of diazoxide to induce relaxant effects was lost when mesenteric rings were exposed to high $\mathrm{K}^{+}$ concentrations in the extracellular medium. This phenomenon is reinforced by results obtained with mesenteric rings maintained in the presence of a high- $\mathrm{K}^{+}$solution containing phenylephrine. Under a depolarizing stimulus induced by the high content of $\mathrm{K}^{+}$in the extracellular compartment, diazoxide induced a lower relaxant effect in the phenylephrine-induced contraction. Such lack of efficacy can be understood if we consider the comparison between the equations within the concentration range of $\mathrm{K}^{+}$where the predicted results approach one to another. If the values calculated by Nernst or Goldman-Hodgking-Katz equations are coincident, the opening of $\mathrm{K}^{+}$channels will be useless, and hyperpolarization could not occur. This is reflected in vascular smooth muscle cells as the maintenance of a given contraction already established at its original level without the observation of any relaxant effect.

\section{Evaluation of Student Work}

The impact of this activity on student comprehension regarding the bioelectrical potential concept was evaluated by means of a questionnaire applied before and after the activity. From the student responses, it should be noted that incorrect answers to questions on the pretest about whether the electrical potential difference increases or decreases under certain conditions, or whether the transmembrane potential is more negative or less positive, were less frequent in the questionnaires answered by the students after the activity.

The experiment as described here is guided inquiry: the instructors generated the question(s) and the students designed the experiment. Students should have free access to microcomputers to calculate the results of Nernst and Goldman-Hodgkin- 
A

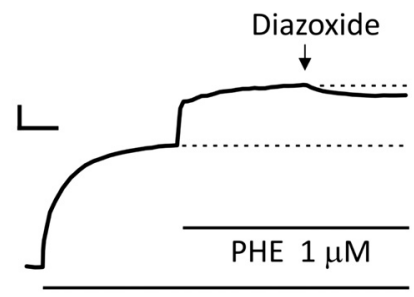

$\mathrm{K}^{+} 60 \mathrm{mM}$

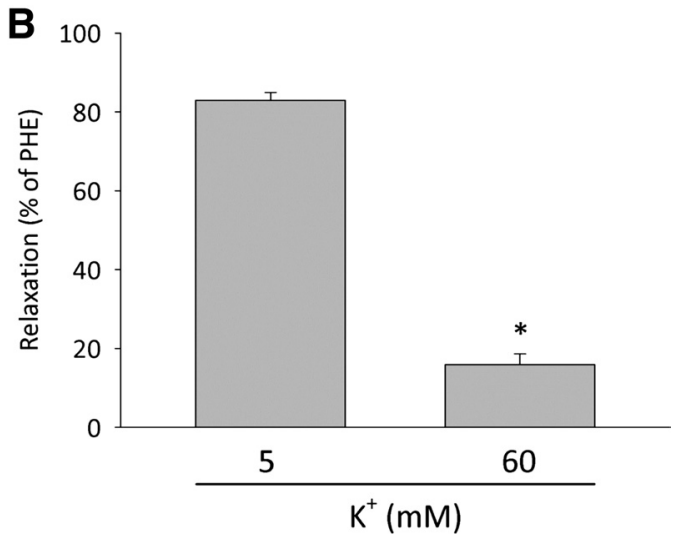

Fig. 6. Relaxant effects of diazoxide on the contraction induced by phenylephrine in rings of the rat mesenteric artery exposed to 5 or $60 \mathrm{mM} \mathrm{K}^{+}$. $A$ : typical recording traces showing the contraction of a rat mesenteric artery ring induced by $60 \mathrm{mM} \mathrm{K}^{+}$. When the steady state was reached, phenylephrine $(1 \mu \mathrm{M})$ was added, yielding a further contraction. Diazoxide $(100 \mu \mathrm{M})$ was added on the new plateau of the combined contraction, and only a slight relaxation was observed, in contrast to its relaxation effect, as shown in Fig. $2 B$. The dashed line at the center of this graph indicates the baseline considered that would be potentially reached if the relaxant effect of diazoxide did not putatively depend of the depolarizing action induced by the high $\mathrm{K}^{+}$concentration. Calibrations: vertical, $100 \mathrm{mg}$; horizontal, $3 \mathrm{~min}$. $B$ : graph showing that the relaxant effect of diazoxide on phenylephrine-induced contraction was higher when ring preparations were maintained under $5 \mathrm{mM}$ than under $60 \mathrm{mM}$ $\mathrm{K}^{+}$. Data are means \pm SE. $* P<0.05$ (by an unpaired Student's $t$-test).

Katz equations. Under lecturer supervision, students constructed the concentration-effect curve, and free discussion of results was stimulated to occur throughout the activity. Concentrations of $\mathrm{K}^{+}$or diazoxide may be chosen by the students, but instructors should be aware that low concentrations may produce no functional effects, and they should instruct the students to increase such concentrations during the experiment. On the other hand, very high concentrations should be avoided because unspecific effects may be produced. Graphic representation of the results should be encouraged in this activity.

\section{Wider Educational Applications}

An interesting result was obtained from question 8 in Table 3. This question dealt with the consequences of closing plasmalemmal $\mathrm{K}^{+}$channels on the resting membrane potential of a smooth muscle cell. It is worth highlighting that the number of correct responses was higher after the activity, mainly from those students that responded "I do not know" before the activity. Although not specifically addressed at any time in the course of the activity, the increase in the number of correct responses reveals that student's comprehension may evolve to a deeper understanding of other events clinically relevant, which are based on the concept of bioelectrical potential. For instance, it is well known that diabetes mellitus may be treated with insulin secretagogues, which act by closing inward rectifier ATP-sensitive $\mathrm{K}^{+}$channels, reducing the efflux of $\mathrm{K}^{+}$ through the channel and causing depolarization (6). Thus, this activity may be useful in some occasions involving certain contexts of problem- or case-based learning.

\section{Additional Resources}

For additional peer-reviewed reports on this topic, please see Refs. 8, 9, 22, and 24.

Table 3. Student evaluations of the educational value of the practical activity

\begin{tabular}{|c|c|c|}
\hline & $\begin{array}{l}\text { Before } \\
\text { the } \\
\text { Activity }\end{array}$ & $\begin{array}{l}\text { After } \\
\text { the } \\
\text { Activity }\end{array}$ \\
\hline \multicolumn{3}{|c|}{$\begin{array}{l}\text { Question 1. If }[\mathrm{K}]_{\mathrm{e}} \text { increases from } 5 \text { to } 60 \mathrm{mM} \text {, what } \\
\text { happens to a smooth muscle cell? }\end{array}$} \\
\hline Contraction* & 31 & 73 \\
\hline Relaxation & 19 & 1 \\
\hline I do not know & 24 & 0 \\
\hline \multicolumn{3}{|c|}{$\begin{array}{l}\text { Question 2. If }[\mathrm{K}]_{\mathrm{e}} \text { increases from } 5 \text { to } 60 \mathrm{mM} \text {, the } \\
\text { resting membrane potential of a smooth muscle } \\
\text { cell becomes_negative. }\end{array}$} \\
\hline Less* & 28 & 66 \\
\hline More & 30 & 7 \\
\hline I do not know & 16 & 1 \\
\hline \multicolumn{3}{|c|}{$\begin{array}{l}\text { Question 3. Under physiological conditions }\left([\mathrm{K}]_{\mathrm{e}}=\right. \\
5 \mathrm{mM}) \text {, opening of plasmalemmal } \mathrm{K}^{+} \text {channels } \\
\text { produces } \mathrm{K}^{+}\end{array}$} \\
\hline Influx & 17 & 3 \\
\hline Efflux* & 40 & 70 \\
\hline I do not know & 17 & 1 \\
\hline \multicolumn{3}{|c|}{$\begin{array}{l}\text { Question 4. According to question 3, if plasmalemmal } \\
\mathrm{K}^{+} \text {channels open, the resting membrane potential } \\
\text { of a smooth muscle cell becomes __negative? }\end{array}$} \\
\hline Less & 25 & 9 \\
\hline More* & 34 & 63 \\
\hline I do not know & 15 & 2 \\
\hline \multicolumn{3}{|c|}{$\begin{array}{l}\text { Question 5. If the resting membrane potential becomes } \\
\text { less negative, we can say that it }\end{array}$} \\
\hline Increased & 32 & 19 \\
\hline Decreased* & 27 & 55 \\
\hline I do not know & 14 & 0 \\
\hline \multicolumn{3}{|c|}{$\begin{array}{l}\text { Question 6. If the resting membrane potential becomes } \\
\text { more negative, we can say that it }\end{array}$} \\
\hline Increased ${ }^{*}$ & 30 & 55 \\
\hline Decreased & 31 & 19 \\
\hline I do not know & 13 & 0 \\
\hline \multicolumn{3}{|c|}{$\begin{array}{l}\text { Question 7. Consider a smooth muscle cell with a } \\
\text { resting potential of }-60 \mathrm{mV} \text { and a threshold for } \\
\text { excitation of }-50 \mathrm{mV} \text { : if }[\mathrm{K}]_{\mathrm{e}} \text { increases from } 5 \\
\text { to } 7 \mathrm{mM} \text {, the resting potential will be more } \\
\text { the threshold. }\end{array}$} \\
\hline Close to* & 29 & 56 \\
\hline Far from & 15 & 9 \\
\hline I do not know & 30 & 9 \\
\hline \multicolumn{3}{|c|}{$\begin{array}{l}\text { Question 8. Under physiological conditions }\left([\mathrm{K}]_{\mathrm{e}}=\right. \\
5 \mathrm{mM}) \text {, if plasmalemmal } \mathrm{K}^{+} \text {channels are } \\
\text { blocked, the resting membrane potential of a } \\
\text { smooth muscle cells becomes }\end{array}$} \\
\hline Depolarized* & 28 & 42 \\
\hline Hyperpolarized & 30 & 21 \\
\hline I do not know & 26 & 11 \\
\hline
\end{tabular}

Values are numbers of student responses; 74 students total responded anonymously to the questionnaire. $[\mathrm{K}]_{\mathrm{e}}$, extracellular $\mathrm{K}^{+}$concentration. *Expected correct answers. 


\section{ACKNOWLEDGMENTS}

The authors are grateful to C. Militão and G. Vanessa and the students of the "Novos Talentos" Project (Coordenação de Aperfeiçoamento de Pessoal de Nível Superior) for helpful contributions in the organization of this activity.

\section{GRANTS}

This work was supported by Fundação Coordenação de Aperfeiçoamento de Pessoal de Nível Superior, Conselho Nacional de Desenvolvimento Científico e Tecnológico (CNPq), and Universidade Federal do Ceará scholarships as well as by Instituto Nacional de Ciência e Tecnologia-Instituto de Biomedicina do Semi-Árido Brasileiro- $\mathrm{CNPq}$ research grants.

\section{DISCLOSURES}

No conflicts of interest, financial or otherwise, are declared by the author(s).

\section{AUTHOR CONTRIBUTIONS}

Author contributions: H.V.R.-F., D.F.S., A.A.S., and P.J.M. conception and design of research; H.V.R.-F., T.S.d.B., F.J.L., J.P.P., D.F.S., M.T.B.d.S., R.J.S., and V.P.B. performed experiments; H.V.R.-F., J.P.P., D.F.S., R.J.S., F.C., A.A.S., and P.J.M. interpreted results of experiments; H.V.R.-F., A.A.S., and P.J.M. drafted manuscript; H.V.R.-F., T.S.d.B., F.J.L., J.P.P., D.F.S., M.T.B.d.S., R.J.S., F.C., A.A.S., and P.J.M. approved final version of manuscript; T.S.d.B., F.J.L., J.P.P., M.T.B.d.S., R.J.S., F.C., V.P.B., A.A.S., and P.J.M. analyzed data; T.S.d.B., F.J.L., and P.J.M. prepared figures; D.F.S., R.J.S., A.A.S., and P.J.M. edited and revised manuscript.

\section{REFERENCES}

1. Barry PH. Membrane potential simulation program for IBM-PC-compatible equipment for physiology and biology students. Adv Physiol Educ 4: 15-23, 1990.

2. Berridge MJ. Inositol trisphosphate and calcium signaling mechanisms. Biochim Biophys Acta 1793: 933-940, 2009.

3. Bolton TB, Lang RJ, Takewaki T. Mechanisms of action of noradrenaline and carbachol on smooth muscle of guinea-pig anterior mesenteric artery. J Physiol 351: 549-572, 1984.

4. Cardozo DL. A model for understanding membrane potential using springs. Adv Physiol Educ 29: 204-207, 2005.

5. Dwyer TM, Fleming J, Randall JE, Coleman TG. Teaching physiology and the World Wide Web: electrochemistry and electrophysiology on the Internet. Adv Physiol Educ 18: 2-13, 1997.

6. Ferrer R, Atwater I, Omer EM, Gonçalves AA, Croghan PC, Rojas E. Electrophysiological evidence for the inhibition of potassium permeability in pancreatic $\beta$-cells by glibenclamide. $Q J$ Exp Physiol 69: 831-839, 1984.
7. Goldman DE. Potential, impedance, and rectification in membranes. $J$ Gen Physiol 27: 37-60, 1943.

8. Gonzales RJ, Carter RW, Kanagy NL. Laboratory demonstration of vascular smooth muscle function using rat aortic ring segments. $A d v$ Physiol Educ 24: 13-21, 2000.

9. Gross DM, Weitz D. An automated data acquisition system for isolated tissue studies. J Pharmacol Methods 8: 151-159, 1982.

10. Hirst GD, van Helden DF. Ionic basis of the resting potential of submucosal arterioles in the ileum of the guinea-pig. J Physiol 333: 53-67, 1982.

11. Hodgkin AL, Katz B. The effect of sodium ions on the electrical activity of giant axon of the squid. $J$ Physiol 108: 37-77, 1949.

12. Jacobsen JC, Aalkjaer C, Nilsson H, Matchkov VV, Freiberg J, Holstein-Rathlou NH. Activation of a cGMP-sensitive calcium-dependent chloride channel may cause transition from calcium waves to whole cell oscillations in smooth muscle cells. Am J Physiol Heart Circ Physiol 293: H215-H228, 2007.

13. Keynes RD. Nerve and Muscle (4th ed.), edited by Keynes RD, Aidley DJ, Huang CLH. Cambridge: Cambridge Univ. Press, 2011.

14. Milanick M. Changes of membrane potential demonstrated by changes in solution color. Adv Physiol Educ 33: 230, 2009.

15. Minneman KP, Esbenshade TA. $\alpha_{1}$-Adrenergic receptor subtypes. Апnи Rev Pharmacol Toxicol 34: 117-133, 1994.

16. Quast U. Do the $\mathrm{K}^{+}$channel openers relax smooth muscle by opening $\mathrm{K}^{+}$ channels? Trends Pharmacol Sci 14: 332-337, 1993.

17. Silverthorn DU. Uncovering misconceptions about the resting membrane potential. Adv Physiol Educ 26: 69-71, 2002.

18. Somlyo AV, Somlyo AP. Electromechanical and pharmacomechanical coupling in vascular smooth muscle. J Pharmacol Exp Ther 159: 129145, 1968.

19. Standen NB, Quayle JM, Davies NW, Brayden JE, Huang Y, Nelson MT. Hyperpolarizing vasodilators activate ATP-sensitive $\mathrm{K}^{+}$channels in arterial smooth muscle. Science 245: 177-180, 1989.

20. Stuart AE. Teaching neurophysiology to undergraduates using neurons in action. J Undergrad Neurosci Educ 8: A32-A36, 2009.

21. Thurman CL. Resting membrane potentials: a student test of alternate hypotheses. Adv Physiol Educ 14: 37-41, 1995.

22. Vandier C, Le Guennec JY, Bedfer G. What are the signaling pathways used by norepinephrine to contract the artery? A demonstration using guinea pig aortic ring segments. Adv Physiol Educ 26: 195-203, 2002.

23. Videbaek LM, Aalkjaer C, Hughes AD, Mulvany MJ. Effect of pinacidil on ion permeability in resting and contracted resistance vessels. Am J Physiol Heart Circ Physiol 259: H14-H22, 1990.

24. Winn MJ, Panus PC, Norton P, Dai J. Computer system for the acquisition and analysis of vascular contractility. Application to a bioassay of endothelial cell function. J Pharmacol Toxicol Methods 28: 49-55, 1992. 